\title{
Removal of Microplastics from Waters through Agglomeration-Fixation Using Organosilanes-Effects of Polymer Types, Water Composition and Temperature
}

\author{
Michael Toni Sturm 1,2,3, Harald Horn ${ }^{3,4}$ and Katrin Schuhen $1, *$ (D) \\ 1 Wasser 3.0 gGmbH, Neufeldstr. 17a-19a, 71687 Karlsruhe, Germany; info@wasserdreinull.de \\ 2 abcr GmbH, Im Schlehert 10, 76187 Karlsruhe, Germany \\ 3 Karlsruhe Institute of Technology (KIT), Engler-Bunte-Institut (EBI), Chair of Water Chemistry and \\ Water Technology, Engler-Bunte-Ring 9a, 76131 Karlsruhe, Germany; harald.horn@kit.edu \\ 4 DVGW Research Laboratories, Water Chemistry and Water Technology, Engler-Bunte-Ring 9a, \\ 76131 Karlsruhe, Germany \\ * Correspondence: schuhen@wasserdreinull.de; Tel.: +49-721-1565-9593
}

Citation: Sturm, M.T.; Horn, H.;

Schuhen, K. Removal of Microplastics

from Waters through

Agglomeration-Fixation Using

Organosilanes-Effects of Polymer

Types, Water Composition and

Temperature. Water 2021, 13, 675.

https://doi.org/10.3390/w13050675

Academic Editor: Bing-Jie Ni

Received: 26 January 2021

Accepted: 26 February 2021

Published: 2 March 2021

Publisher's Note: MDPI stays neutral with regard to jurisdictional claims in published maps and institutional affiliations.

Copyright: (c) 2021 by the authors. Licensee MDPI, Basel, Switzerland. This article is an open access article distributed under the terms and conditions of the Creative Commons Attribution (CC BY) license (https:// creativecommons.org/licenses/by/ $4.0 /)$.

\begin{abstract}
Due to the fact, that microplastics are a global environmental problem, new ways for their removal from water, soil and air need to be developed. New materials in combination with easy to implement technologies for microplastic removal come into the focus of scientific studies and engineering, especially for application in water resources. In our comparative case study, the effects of water composition and temperature on the agglomeration-fixation reaction of microplastics using organosilanes were examined. We compared biologically treated municipal wastewater, seawater and demineralized water at temperatures ranging from $7.5-40^{\circ} \mathrm{C}$. Temperature variations and tested water compositions showed no negative effect on microplastic removal. The residues of the organosilanes remaining in the water after the fixation process were monitored using ICP-OES and DOC measurements. Only one of the organosilanes tested showed no dissolved residues in the waters. Microplastic encompasses a multitude of different types of polymers with different properties and surface chemistries. Therefore, we compared the efficiency of the process for polyethylene, polypropylene, polyamide, polyester, and polyvinylchloride as examples of common polymer types with different chemical compositions. A strong effect of the polarity of microplastics and organosilanes on removal efficiency was observed. The organic groups of organosilanes can be chemically adapted to different polymer types.
\end{abstract}

Keywords: microplastic removal; sol-gel chemistry; organosilanes; agglomeration; wastewater; seawater; water treatment

\section{Introduction}

Microplastics are one of the most complex environmental problems today. Since the start of mass production in 1950, mismanaged plastic waste has been entering the environment $[1,2]$. Over time, the plastic gets brittle and fragments into smaller and smaller plastic particles. From a size of $5 \mathrm{~mm}$ and smaller, these plastic fragments are defined as microplastics. Additionally, microplastics can enter the environment directly, e.g., textile fibers released through washing or tire abrasion [3,4]. Due to their high persistence the microplastics degrade very slowly and can spread over long distances. Nowadays microplastics can be found in all parts of the aquatic and terrestrial environment as well as in the air $[2,5,6]$. Due to continuously increasing plastic consumption and thus release into the environment, the environment will become increasingly contaminated $[7,8]$. This poses a high risk to the environment and ecosystems as well as to human health $[9,10]$.

Numerous studies identify municipal and industrial wastewater treatment plants as important point sources for microplastics in the environment [11,12]. Despite reported microplastic removal of $95 \%$ to $>99 \%$ from inflowing wastewater to effluent in tertiary 
wastewater treatment plants, the level of microplastic contamination in the influent has such a high level, that the effluent still counts as strongly contaminated. This is especially noticeable, as monitoring of microplastic contamination in the environment shows higher contamination levels after wastewater treatment plant effluents. To prevent the release into the environment, there is a need for improved microplastic removal during the wastewater treatment process.

Additionally, there are several microplastic sensitive seawater using processes. One example is membrane-based seawater desalination, where microplastics pose the risk for membrane fouling $[11,13]$. Near food chain processes, such as sea salt production, can transport the microplastics from the environment to human food and therefore pose a risk to human health $[9,14,15]$. To ensure the functionality of microplastic sensitive water using processes there is a need for a method to remove microplastics from water cost effectively and with low technical effort $[11,16,17]$.

Filtration is a common method for the removal of solids during water treatment and can also be applied for microplastic removal $[11,18]$. But the smaller the particles get, the more complex and expensive the filtration process gets. Therefore, processes like membrane filtration have disadvantages such as high investment costs, high energy consumption and high maintenance, due to, for example, the scaling and fouling of the membranes. An easier method could be dissolved air flotation (DAF) [11]. However, different studies showed insufficient removal efficiencies of microplastics [19].Even in combination with flocculants and surface modifiers Wang et al. 2020 could only reach values between $68.9 \%$ and $43.8 \%$ for microplastic removal using DAF [20]. Microplastics can consist of a multitude of different types of polymers with different properties and surface chemistries. These can have a strong influence on the interaction of flocculants and microplastics and make finding suitable flocculants even more challenging [13,21]. Most commonly used flocculants are based on iron or aluminum and therefore have a limited adaptability [21]. Polyelectrolyte based flocculants are more adaptable, but due to their solubility they remain in the water and can cause harm to aquatic organisms and ecosystems [22,23].

Facing this challenge, Herbort et al. 2016 developed a new approach to remove microplastics from water using organosilanes (Figure 1) [24-28]. The organosilanes consist of one organic group and three reactive groups. Due to the interaction of the organic group and the surface of the microplastics, the organosilanes attach to the surface of the microplastic and collect it in agglomerates in the first step of the fixation process [25]. In the second step of the fixation, the three reactive groups form a solid hybrid silica gel that includes and fixes the microplastics chemically driven by a water induced sol-gel process. During this sol-gel process, the reactive groups are hydrolyzed to highly reactive silanols, which subsequently condensate and form siloxane bonds [27,29].

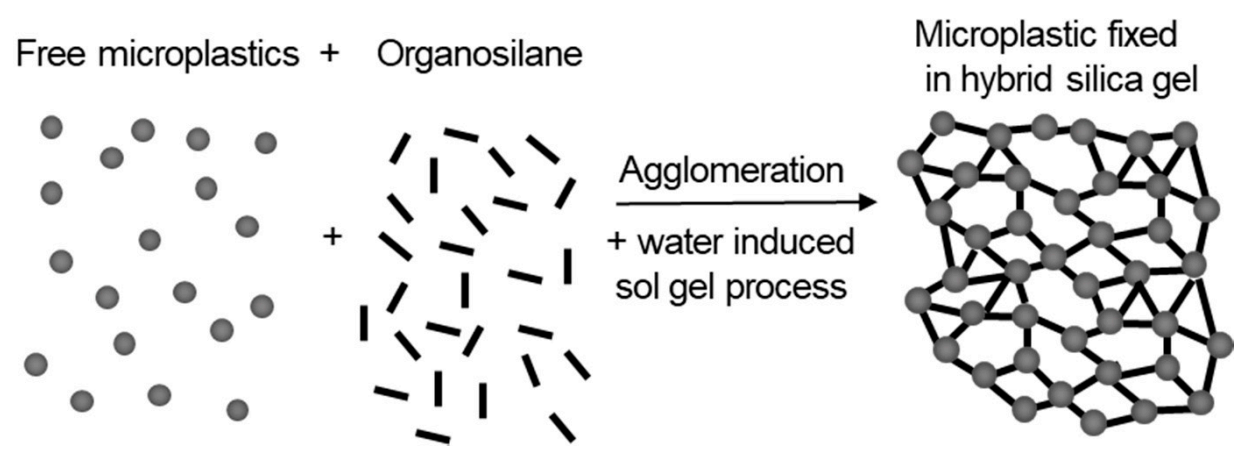

Figure 1. Agglomeration-fixation reaction: Removal of microplastics from water using organosilanes. Organosilanes attach to the surface of microplastics, collect it in large agglomerates and chemically fix it by forming a solid hybrid silica in a water induced sol-gel process. 
The novelty of this process is the combination of a physical agglomeration process with a water induced chemical fixation process, leading to strong particle growth and stable agglomerates $[25,26]$. Hence, the organic groups can be adapted to different polymer types and surface chemistries. The reactivity of the organosilanes can be adapted to different water compositions by changes in reactive groups and organic groups [26,27]. The high diversity and adaptability of organosilanes as chemical substance class gives this relatively new and little researched approach a high potential for application in water treatment and microplastic removal.

So far the process has been tested to remove polyethylene and polypropylene based microplastics on lab scale using demineralized water and on pilot plant scale from tap water $[25,27]$. To investigate the transferability to processes in sea water and wastewater, it is tested how water compositions affect the removal process, as dissolved ions, natural organic matter or surfactant compounds can affect the sol-gel process and thus the removal process [28]. Also, the influence of water temperatures is tested, as it can vary depending on climatic conditions or wastewater origin. As the formation of silanol groups enhances water solubility, possible organosilane residues remaining dissolved in the water after the fixation process are monitored. To exclude potential discharge, no organosilanes may remain dissolved in the water after the process is finished. Additionally, the process was tested for common polymer types with different properties and surface chemistries, to investigate how those affect the interaction with the organosilanes and the agglomerate formation. By the combined investigation of these new and important factors, we want to bring microplastic removal by organosilanes one step further towards the application transfer.

\section{Materials and Methods}

\subsection{Used Microplastics and Chemicals}

Table 1 shows the polymer types, mean size and suppliers of the used microplastics (Figure S1).

Table 1. Overview of microplastics used in the experiments.

\begin{tabular}{cccc}
\hline Polymer Type & Abbreviation & Mean Size $[\mu \mathrm{m}]$ & Supplier \\
\hline $\begin{array}{c}\text { Mixture of } \\
\text { Polyethylene/Polypropylene }\end{array}$ & PE/PP & $318 \pm 258$ & $\begin{array}{c}\text { LyondellBasell, Basell } \\
\text { Polyolefine GmbH, Frankfurt, } \\
\text { Germany }\end{array}$ \\
$\begin{array}{c}\text { Polyamide } \\
\text { Polyester }\end{array}$ & PA & $357 \pm 60$ & $\begin{array}{c}\text { EMS-Grilltech, Domat/Ems, } \\
\text { Switzerland }\end{array}$ \\
EMS-Grilltech, Domat/Ems, \\
Switzerland \\
Polyvinylchloride & PES & $54 \pm 87$ & $\begin{array}{c}\text { Sigma-Adlrich, Taufkirchen, } \\
\text { Germany }\end{array}$ \\
\hline
\end{tabular}

The organosilanes n-butyltrichlorosilane (CAS 7521-80-4), isooctyltrichlorosilane (CAS 18379-25-4), (3-chloropropyl)trichlorosilane (CAS 2550-06-3) and abcr eco Wasser 3.0 PE- $X^{\circledR}$ (AB930009), a mixture of organosilanes, were provided by abcr GmbH, Karlsruhe, Germany. abcr eco Wasser 3.0 PE- $X^{\circledR}$ is abbreviated as PE-X.

\subsection{Different Water Types and Temperatures}

We compared the removal process in demineralized water, salt water and biologically treated municipal wastewater (secondary clarifier). The salt water was created by dissolving $3.5 \%$ by weight of untreated Atlantic sea salt (Art. No. 8530, Biova, Wildberg, Germany) in demineralized water. The biologically treated wastewater was taken from the sewage treatment plant at Landau i. d. Pfalz, Germany on 2 March 2020 (after several days of rain). The water parameters can be seen in Table S1. Both water samples were filtered through a $0.6 \mu \mathrm{m}$ paper filter (Macherey-Nagel MN 85/70 BF) to remove all solids 
contained. To compare the influence of different temperatures, the water samples were adjusted to $7.5,20$ and $40^{\circ} \mathrm{C}$ using ice baths or heating plates.

\subsection{Determination of Removal Efficiency}

The removal efficiency was determined gravimetrically according to Sturm et al. 2020 [27]. $1 \mathrm{~L}$ of water was filled into a $2 \mathrm{~L}$ beaker, the microplastic was added and the suspension was stirred using a magnetic stirrer for $5 \mathrm{~min}$ at the highest speed. Subsequently, the stirrer was set to $500 \mathrm{rpm}$, the organosilane was added and the mixture was stirred for $20 \mathrm{~min}$ to perform the agglomeration process. After $20 \mathrm{~min}$, the contents of the beaker were filtered through an analysis sieve (stainless steel, mesh size $1 \mathrm{~mm}$, diameter $20 \mathrm{~cm}$ ). Therefore, agglomerates larger than $1 \mathrm{~mm}$ remained in the sieve and were classified as removed. The filtrate with the remaining free microplastic was repeatedly filtered through a filter crucible (porosity 4, max. pore size $16 \mu \mathrm{m}$ ) and rinsed with isopropanol to remove possible attached organosilane residues. After drying the sample at $105{ }^{\circ} \mathrm{C}$ for $24 \mathrm{~h}$, the weight of the free microplastic could be determined.

Unless otherwise stated, the organosilane dosage was $100 \mu \mathrm{L} / \mathrm{L}$ and microplastic concentration was $100 \mathrm{mg} / \mathrm{L}$. Performing lab scale experiments using $1 \mathrm{~L}$ water, $100 \mathrm{mg}$ microplastics per liter was the lowest concentration possible to achieve reliable and reproducible results. An organosilane dosage of $100 \mu \mathrm{L} / \mathrm{L}$ was chosen, as in previous studies it turned out to be the lowest concentration to remove $100 \mathrm{mg}$ PE/PP efficiently ( $>95 \%$ ) from water on laboratory scale. The size limit for the agglomerates to be classified as removed was set to $1 \mathrm{~mm}$, as from this size the agglomerates proved to be easy to remove in pilot plant experiments. Microplastics that stick to the wall or the bottom of the beaker and cannot be removed by rinsing thoroughly with the wash bottle are also considered as removed.

\subsection{Determination of the Organosilane Residues Dissolved in Water}

To measure the dissolved organosilane residues, the standardized removal process was conducted using $100 \mathrm{mg} / \mathrm{L}$ of a PE/PP mixture (1:1) as microplastics. After 20 min stirring time, a water sample was taken and filtered through a $0.45 \mu \mathrm{m}$ syringe filter. The silicon concentration of the sample was measured using an ICP-OES spectrometer (Inductive Coupled Plasma Optical Emission Spectroscopy) (Agilent Technologies, ICP-OES 5110, Waldbronn, Germany). The DOC concentration (dissolved organic carbon) was measured with the Sievers TOC Analyzer 820. Blank values from the respective water samples were subtracted from the measured values.

\subsection{Additional Analytics}

To determine the mean size, 20 microplastic particles respectively ten agglomerates were photographed with the stereomicroscope SMT4 from ASKANIA Mikroskop Technik Rathenow GmbH, Rathenow, Germany coupled with a Canon EOS 600D digital camera and subsequently measured.

IR spectra $\left(4000-300 \mathrm{~cm}^{-1}\right.$, resolution $\left.1 \mathrm{~cm}^{-1}\right)$ of the aggregates and hybrid silica gels, which had been dried previously for $24 \mathrm{~h}$ at $105^{\circ} \mathrm{C}$, were taken with the ATR-FTIR spectrometer Vertex 70, Bruker, Ettlingen, Germany.

Thermogravimetric analysis (TGA) was conducted using a Q5000 IR from TA Instruments using a platinum crucible. Starting temperature was $45^{\circ} \mathrm{C}$, purge gas 1: nitrogen 5.0; $25 \mathrm{~mL} / \mathrm{min}$ with a heating rate of $20^{\circ} \mathrm{C} / \mathrm{min}$. The gas switching temperature was at $600{ }^{\circ} \mathrm{C}$, purge gas 2: oxygen $5.0 ; 0.25 \mathrm{~mL} / \mathrm{min}$ with a heating rate of $20^{\circ} \mathrm{C} / \mathrm{min}$ and final temperature of $950^{\circ} \mathrm{C}$.

\section{Results and Discussion}

\subsection{Different Water Types and Temperatures}

The comparison of the removal efficiencies at different temperatures (Figure 2) shows no negative impacts of high or low temperatures on the removal process. Also, no sig- 
nificant differences can be seen among the different organosilanes. All values are within the standard deviations respectively measurement fluctuations. The process should therefore be applicable without problems at high temperatures, which can occur in industrial wastewaters and at low temperatures, which can occur in the winter months in natural waters or different wastewaters [30,31].

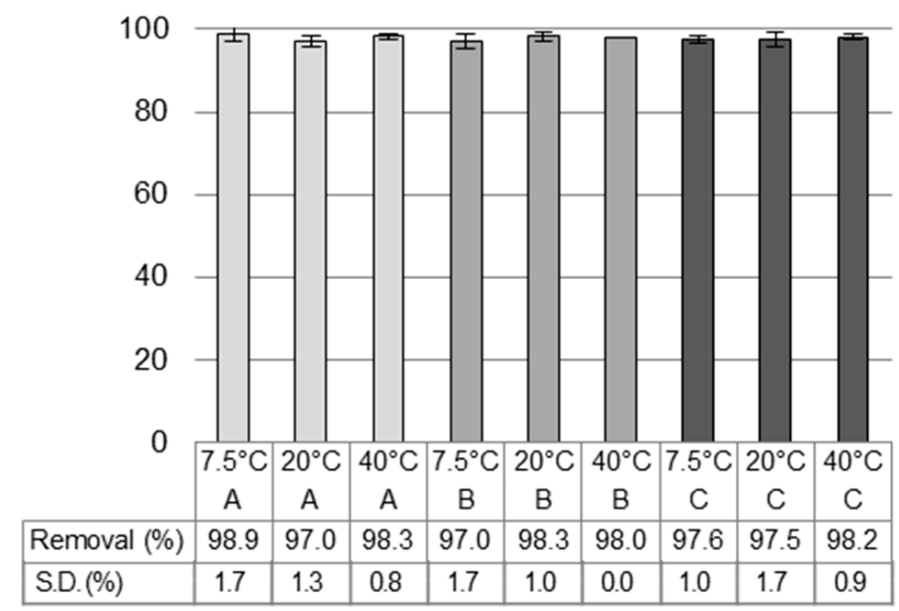

Figure 2. Removal efficiency for $100 \mathrm{mg}$ mixture of PE/PP (1:1) from $1 \mathrm{~L}$ demineralized water at different temperatures using $100 \mu \mathrm{L}$ organosilane $(\mathrm{A}=\mathrm{PE}-\mathrm{X} ; \mathrm{B}=\mathrm{n}$-Butyltrichlorosilane; $\mathrm{C}=$ Isooctyltrichlorosilane).

This could be shown analogously for different water types. The three different water types show no significant differences regarding the removal process (Figure 3). Measurement fluctuations caused the lower removal efficiency using isooctyltrichlorosilane in salt water, which is also expressed in the higher standard deviation. Due to turbulent flow conditions in the experimental setup, inducing random movement of agglomerates and microplastics, such fluctuations can occur [14]. On pilot plant scale the flow conditions and fluctuations can be controlled better due to advanced steering and mixing mechanisms.

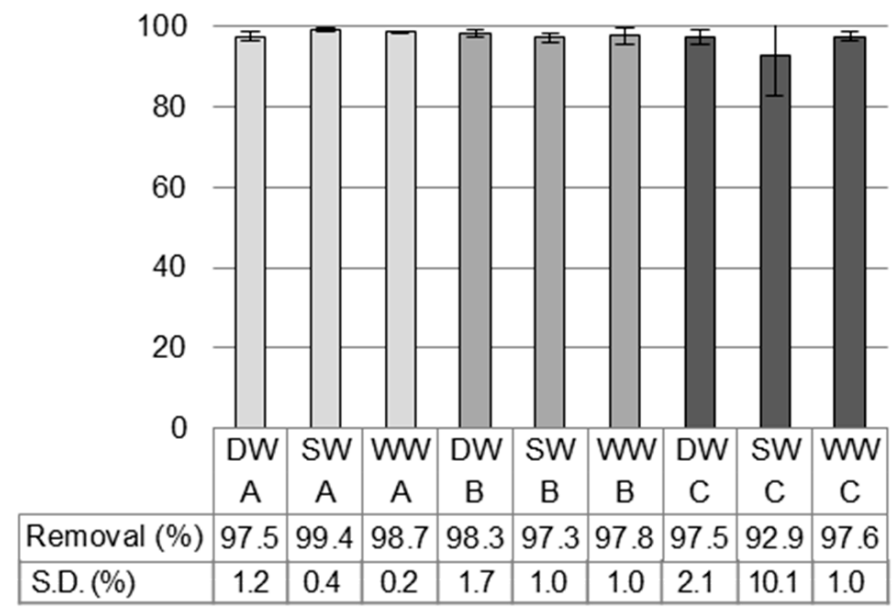

Figure 3. Removal efficiency for $100 \mathrm{mg}$ mixture of PE/PP (1:1) from $1 \mathrm{~L}$ demineralized water (DW), salt water (SW) or biologically treated wastewater (WW) using $100 \mu \mathrm{L}$ organosilane (A = PE-X; $\mathrm{B}=\mathrm{n}$-Butyltrichlorosilane; $\mathrm{C}=$ Isooctyltrichlorosilane).

Possible positive impacts of sea- or wastewater could not be examined with the applied parameters, since the combination of $100 \mathrm{mg}$ of microplastics in one liter of water with $100 \mu \mathrm{L}$ of organosilane was selected in such a way that it had achieved optimum removal $(>95 \%)$ with demineralized water as a reference, which leaves no room for measurable improvements. 
In general, wastewater shows temporal variations on the chemical composition and particle load but also variations depending on the catchment area [32]. In our experiments, we decided to test municipal wastewater, taken during a rainy period, as it contains more microplastic washed from the roads by surface runoff (e.g., tire wear) and poses one of the biggest point sources for microplastics into the environment [33,34]. Besides, the wastewater is diluted with rainwater and usually contains less nutrients and other chemicals as surfactants. On the day of sampling, the inflow amounted to 38 million Liter $(\mathrm{L})$, whereas the average inflow on dry days amounts to 11 million $\mathrm{L}$ per day. Although we could not find any negative effect in the wastewater used in our studies, further investigations should focus on the variations of wastewater compositions. Especially industrial wastewater can show strong variations depending on the type of industry [35].

For salt water, oceans show spatial and temporal variations for the salt concentration and composition [36]. The salt concentration usually varies between $3.2-3.8 \%$, with an average of $3.5 \%$, which we chose as the concentration for the experiments. As there is no difference between demineralized water and 3.5\% salt water, the fluctuations of salt concentrations in the oceans should be negligible. Only saline lakes, which can easily reach salt concentrations $>10 \%$ and are often used for salt extraction, could affect the process [37]. Nevertheless, the removal process should be transferable to municipal wastewater and sea water. The functionality of the process in drinking water could already be proven in a previous study [25].

\subsection{Comparison of Polymer Types}

Comparing the efficiency of the removal process with different types of polymers, clear differences between the types of polymers and the organosilanes used could be determined (Figure 4). During the removal process, the organic groups of the organosilanes needs to attach to the surface of the microplastic particles to collect them in agglomerates. Therefore, these differences are caused by the varying interactions of the organic groups and the surface of the different polymer types [27].

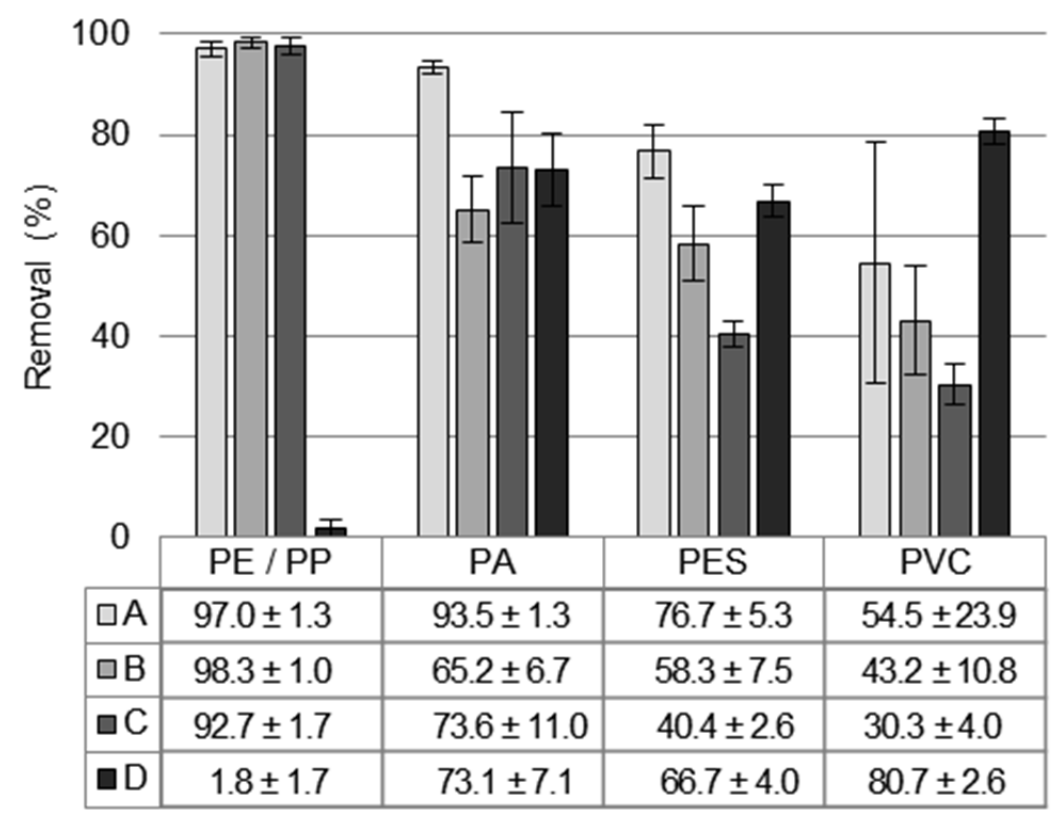

Figure 4. Removal efficiency for $100 \mathrm{mg}$ microplastics from $1 \mathrm{~L}$ demineralized water using $100 \mu \mathrm{L}$ organosilane $(\mathrm{A}=\mathrm{PE}-\mathrm{X} ; \mathrm{B}=\mathrm{n}$-Butyltrichlorosilane; $\mathrm{C}=$ Isooctyltrichlorosilane; $\mathrm{D}=$ (3-Chloropropyl)trichlorosilane).

PE and PP consist of pure alkyl chains, have no heteroatoms and are, therefore, nonpolar. PA has nitrogen and oxygen and PES oxygen as heteroatoms, which is why they are more polar. However, since the $\mathrm{C}-\mathrm{H}$ component predominates, they are classified 
with medium polarity. PVC results from the crosslinking of vinyl chloride $\left(\mathrm{C}_{2} \mathrm{H}_{3} \mathrm{Cl}\right)$, which means that it has an extremely high proportion of chlorine atoms and the highest polarity in the polymer series shown.

Among the organosilanes, PE-X, n-butyltrichlorosilane and isooctyltrichlorosilane have non-polar organic groups made of pure hydrocarbons. In the tests with microplastics based on PE and PP, satisfactory removal efficiencies between 97 and $98.3 \%$ were consistently reached. However, with increasing polarity of the microplastics, the effectiveness decreased, as much smaller agglomerates are formed which partially do not reach the size limit of $1 \mathrm{~mm}$ (Figure 6). With very polar PVC values between 30-55\% can be achieved. Another influence factor could the higher density of the polar polymer types, as it can hinder the accumulation of the microplastics and smaller agglomerates in the vortex by sinking.

In comparison Lapointe et al. 2020 tested aluminum and polyacrylamide based flocculants towards weathered and unweathered PE and could show that the introduction of polar hydroxyl and carboxylic acid groups by weathering could improve the interaction of the flocculants and microplastics leading to improved removal [21]. This result shows that coagulants with polar sorption sites can lead to enhanced flocculation of polar microplastics.

Therefore, (3-chloropropyl)trichlorosilane was added to the tested organosilanes, which has a higher polarity due to a chlorine substitution at the end of the organic propyl group. This creates an improved interaction with the surface polar polymers. For the highly polar PVC a clear improvement of the removal efficiency is reached. In the case of polymers of medium polarity (PES and PA), which have both polar and non-polar structural units, no clear improvement could be achieved by the chlorine substitution. Using PE/PP, no agglomerate formation was observed, since there was no interaction between the non-polar surface and the polar chloropropyl group. These results prove the strong interaction between the organic group of the organosilanes and the surface of the microplastics depending on the polymer type.

Because chlorinated hydrocarbons are generally both ecotoxicologically hazardous and harmful to health, the use of (3-Chloropropyl)trichlorosilane in actual application is unlikely [38]. Due to the good results achieved by the chemical modification of the organic group, future studies should focus on environmentally friendly alternatives for organosilanes with polar organic groups. For this adaption however, it must also be taken into account that the organic groups can have a strong influence on the reactivity of the organosilanes and thus can negatively influence the fixation process [27]. Therefore, not all organic groups are suitable for this adaptation.

Additionally, a higher dosage or combination of organosilanes was tested for the removal of PVC (Figure 5). An increase in the dosage to $300 \mu \mathrm{L}$ n-butyltrichlorosilane (84.0\%) and the combination of $100 \mu \mathrm{L}$ PE-X with an additional $100 \mu \mathrm{L}$ isooctyltrichlorosilane (79.6\%) respectively $100 \mu \mathrm{L}$ n-butyltrichlorosilane (77.6\%) show an increase in efficiency comparable to (3-chloropropyl)trichlorosilane $(80.7 \%)$. This shows the potential of the combination of organosilanes for microplastic removal and that there is still potential for further improvement of PE-X. Using a dosage of $1 \mathrm{~mL} \mathrm{n}$-butyltrichlorosilane, an almost complete removal could be achieved reaching $98.1 \%$. Studies using aluminum, iron or polyacrylamide based flocculants also showed increased effectivity of higher dosages [13,21].

The mean size of the microplastics and the agglomerates is shown in Figure 6. It can be seen, that the size composition of the virgin microplastics differs significantly among the polymer types and mixtures. CoPA $(\varnothing 357 \mu \mathrm{m})$ and PE/PP $(\varnothing 318 \mu \mathrm{m})$ have a larger starting size than PVC $(\varnothing 110 \mu \mathrm{m})$ and CoPES $(\varnothing 54 \mu \mathrm{m})$. Additionally, the standard deviations show that PVC and PA particles have a more even size while the size of PES and PE/PP particles show large deviations. It is currently unclear whether the initial size of the microplastics has an influence on the final size of the agglomerates, as data shows strong particle growth during the agglomeration process for all polymer types. In previous studies testing flocculation of microplastics with different size compositions using iron, 
aluminum and polyacrylamide based flocculants, larger microplastic particles showed worse flocculation as they are more difficult to incorporate into the flocks [13,21].

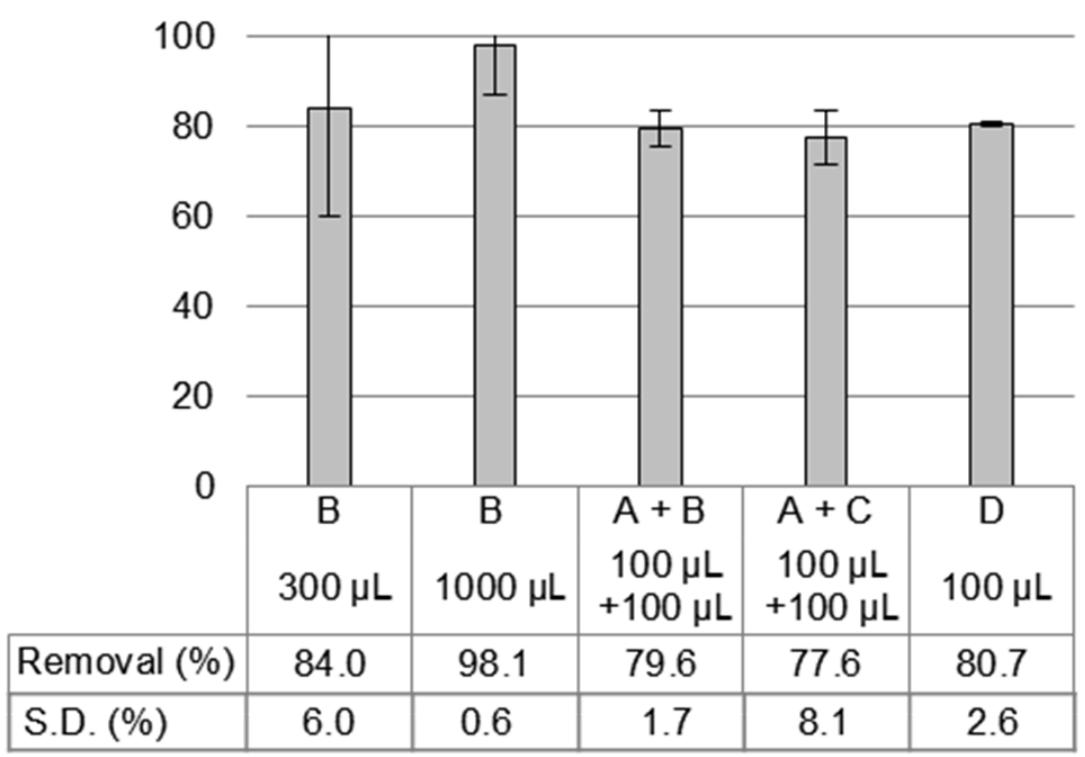

Figure 5. Removal efficiency for $100 \mathrm{mg}$ PVC from $1 \mathrm{~L}$ demineralized water using $100 \mu \mathrm{L}$ organosilane at different dosages and combinations $(\mathrm{A}=\mathrm{PE}-\mathrm{X} ; \mathrm{B}=\mathrm{n}$-Butyltrichlorosilane; $\mathrm{C}=$ Isooctyltrichlorosilane; $\mathrm{D}=$ (3-Chloropropyl)trichlorosilane).

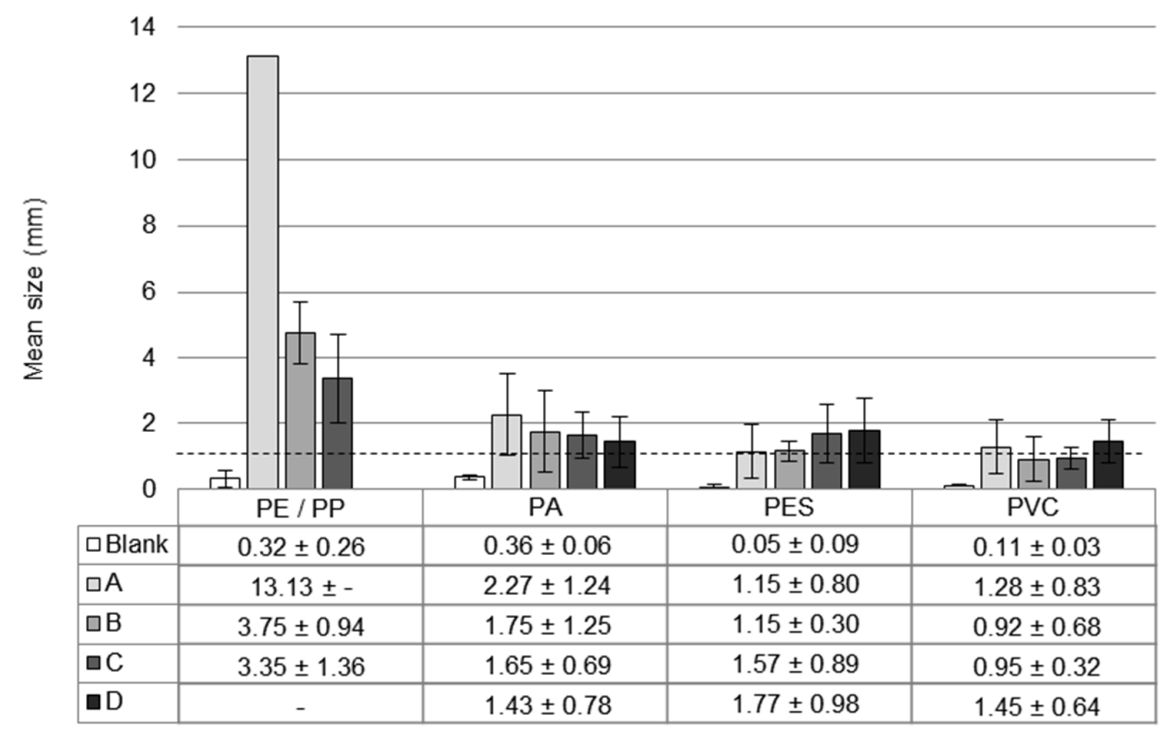

Figure 6. Mean size of microplastics and agglomerates. The dashed black line marks the $1 \mathrm{~mm}$ limit from which the microplastics are assessed as removed. (A = PE-X; $\mathrm{B}=\mathrm{n}$-Butyltrichlorosilane; $\mathrm{C}=$ Isooctyltrichlorosilane; $\mathrm{D}=$ (3-Chloropropyl) trichlorosilane).

Ma et al. 2019 reported flock sizes of $258.6 \pm 20.8 \mu \mathrm{m}$ using aluminium-based flocculants and $474.8 \pm 25.6$ for iron-based flocculants for the removal of PE. Lapointe et al. 2020 reported flock diameters of $977 \pm 36 \mu \mathrm{m}$ for the removal of PE $<140 \mu \mathrm{m}$ and of $504 \pm 18 \mu \mathrm{m}$ for PE $>140 \mu \mathrm{m}$ applying polyacrylamide-based flocculants. Compared to this, using organosilanes higher agglomerate sizes could be reached for the removal of $\mathrm{PE} / \mathrm{PP}$ with up to $13,130 \mu \mathrm{m}$ using PE-X. Also it is notable that on pilot plant scale much higher agglomerate sizes could be achieved [25]. This is a big advantage of this method, as larger agglomerates can be removed more easily. 
For the determination of the removal efficiency, the limit for agglomerates classified as removed was set at $1 \mathrm{~mm}$, since those could easily be removed in pilot plant tests in a $2 \mathrm{~m}^{3}$ test reactor system [27]. Considering the mean size and standard deviations of the agglomerates, for PA, PES and PVC a proportion of the agglomerates do not reach the size of $1 \mathrm{~mm}$ and therefore are classified as free microplastics despite a strong particle growth compared to the initial size. Thus, by optimizing the agglomerate removal on pilot plant scale and therefore lowering the size limit for the removal, a strong increase in removal efficiency can be expected.

\subsection{Organosilanes Residues Dissolved in Water}

The examination of the organosilane residues dissolved in water (Figure 7) shows that for isooctyltrichlorosilane and n-butyltrichlorosilane, between 76.4 and $46.3 \%$ of the added organosilane (calculated based on the Si content) remains in solution. This happens as the silanols formed during the hydrolysis of the chlorine groups increase the water solubility of the organosilanes [39]. During the sol-gel process formed oligomers or dimers with remaining silanol groups can remain in solution and not react completely to solid hybrid-silica gels. This poses a problem for a technical application of the fixation process. However, this effect cannot be seen with PE-X, as no residues could be detected in the water. Therefore, PE- $\mathrm{X}$ is suitable for the application.
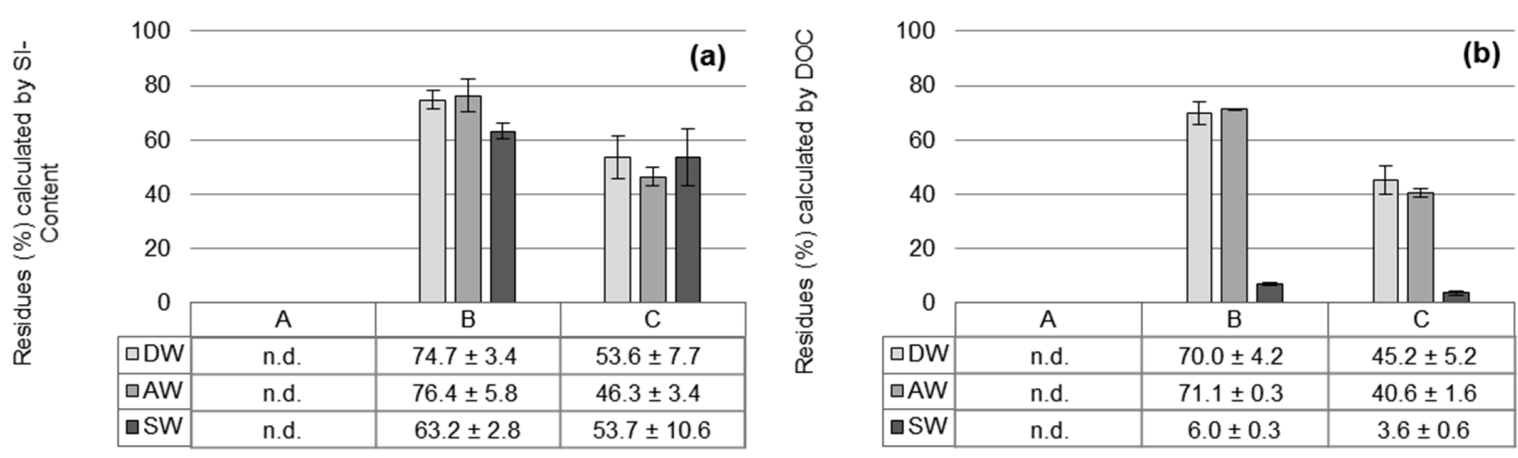

Figure 7. Percentage of organosilane residues in the water calculated from the Si content (a) and DOC content (b) after adding $100 \mathrm{mg}$ PE/PP (50:50) in $1 \mathrm{~L}$ water, subsequently adding $100 \mu \mathrm{L}$ organosilane and stirring for $20 \mathrm{~min}$. (DW = demineralized Water; $\mathrm{SW}=$ salt water; $\mathrm{WW}=$ biological treated wastewater; $\mathrm{A}=\mathrm{PE}-\mathrm{X} ; \mathrm{B}=\mathrm{n}$-butyltrichlorosilane; $\mathrm{C}=$ isooctyltrichlorosilane). For DOC $100 \%$ correspond to $\mathrm{A}=58.7 \mathrm{mg} / \mathrm{L}, \mathrm{B}=29.1 \mathrm{mg} / \mathrm{L}$ and $\mathrm{C}=41.8 \mathrm{mg} / \mathrm{L}$. For Si content $100 \%$ corresponds to $\mathrm{A}=17.2 \mathrm{mg} / \mathrm{L}, \mathrm{B}=17 \mathrm{mg} / \mathrm{L}$ and $\mathrm{C}=12.1 \mathrm{mg} / \mathrm{L}$.

Comparing the results of the DOC and Silica concentrations, it is noticeable that the residues measured with the ICP-OES (Si content) are always slightly higher than the values measured by DOC. At the start of the DOC measurement, highly concentrated phosphoric acid is added to the sample in order to remove the contained inorganic carbon. This acid catalyzes the sol-gel process, which means that dissolved dimers and oligomers contained in the sample can condense, precipitate and deposit on tubes [29]. This effect is particularly noticeable in salt water, as the combination of acid and dissolved salt additionally intensifies the condensation of the oligomers.

In general, ICP-OES delivers more accurate and reliable measured values, due to the short distance from the intake to the plasma torch and the general robustness of the measuring method. DOC is a good alternative for process control, as it is a cheap and easy to handle method.

\subsection{Additional Analytics}

\subsubsection{Microscope Images}

The microscope images (Figure 8 and Figure S1) show the formation of stable agglomerates, where the microplastics are held together by the organosilane. As the organosilane forms a thin, transparent to slightly white hybrid silica layer on the microplastics during 
the formation process, the single microplastics particles can still be recognized. The texture of the agglomerate is tough and viscoelastic, which is typical for hydrogels [40]. In addition, the agglomerates are very sticky and attach to glass, metal, and plastic surfaces.
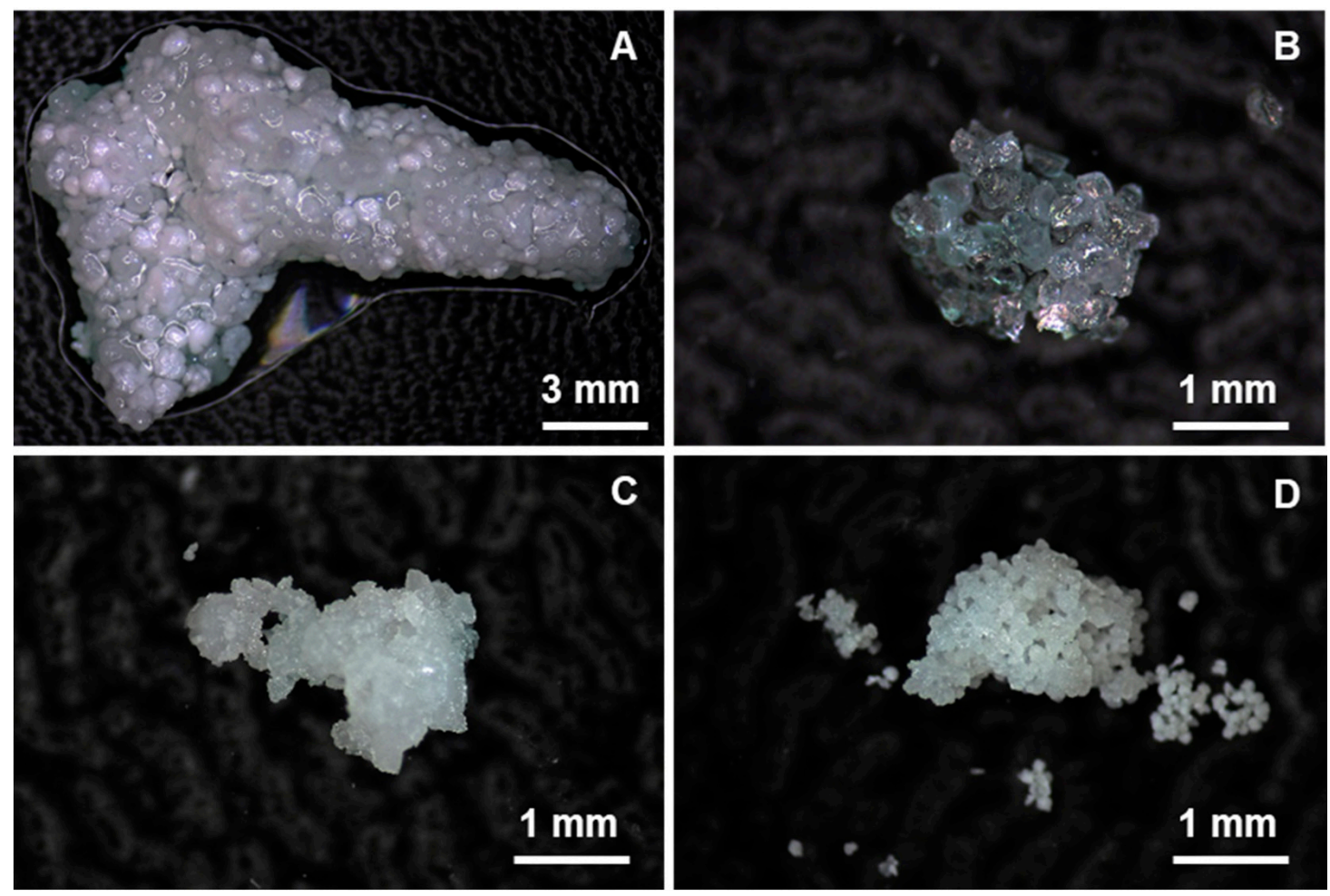

Figure 8. Microscope images of wet agglomerates formed during the removal of $100 \mathrm{mg}$ microplastics from $1 \mathrm{~L}$ demin, water using $100 \mu \mathrm{L}$ organosilane. (A) = PE-X and PE/PP (1:1), (B) = n-Butyltrichlorosilane and PA, (C) = Isooctyltrichlorosilane and PES, (D) = (3-Chloropropyl)trichlorosilane and PVC.

\subsubsection{IR-Spectra}

Figures S2-S7 show the IR spectra of the different polymers, the hybrid silica resulting from the respective organosilane after $20 \mathrm{~min}$ water contact and the agglomerates formed during the removal process. The IR spectra of the hybrid silica gels show small peaks for the siloxane bonds at $1200-1240 \mathrm{~cm}^{-1}\left(v_{\text {as }} \mathrm{Si}-\mathrm{O}-\mathrm{Si}\right)$, a wide peak of $1100-1000 \mathrm{~cm}^{-1}$ $\left(v_{\text {as }} \mathrm{Si}-\mathrm{O}-\mathrm{Si}\right)$ and a peak at $390-460 \mathrm{~cm}^{-1}(\delta \mathrm{O}-\mathrm{Si}-\mathrm{O})[25,41]$. The deformation oscillations of the alkyl groups $\left(\delta_{\mathrm{S}} \mathrm{C}-\mathrm{H}, \delta_{\mathrm{as}} \mathrm{C}-\mathrm{H}, \delta-\mathrm{CH} 2-\right)$ can be seen in the range of $1260-1470 \mathrm{~cm}^{-1}$. The stretching vibrations of the alkyl groups $\left(v_{a s} \mathrm{C}-\mathrm{H}, v_{\mathrm{s}} \mathrm{C}-\mathrm{H}\right)$ can be found in the range $2850-2970 \mathrm{~cm}^{-1}$.

These peaks for the alkyl groups can also be found in the spectra of the microplastic samples. Therefore, the agglomerates show stronger peaks of the alkyl groups compared to pure silica, caused by the included microplastics. The presence of PVC in the agglomerate can be confirmed by the peak at $600-650 \mathrm{~cm}^{-1}(\delta \mathrm{C}-\mathrm{Cl})[42,43]$. PA shows additional peaks at $3290 \mathrm{~cm}^{-1}(v \mathrm{~N}-\mathrm{H}), 1630 \mathrm{~cm}^{-1}(\delta \mathrm{C}=\mathrm{O}), 1540 \mathrm{~cm}^{-1}(\delta \mathrm{C}-\mathrm{N}, v \mathrm{~N}-\mathrm{H})$ and $680 \mathrm{~cm}^{-1}(v \mathrm{~N}-\mathrm{H}$; $v C=O)$. Typical PES peaks are visible at $1710 \mathrm{~cm}^{-1}(v \mathrm{C}=\mathrm{O}), 1230 \mathrm{~cm}^{-1}(v \mathrm{C}-\mathrm{O}), 1100 \mathrm{~cm}^{-1}$ $(v \mathrm{C}-\mathrm{O}), 725 \mathrm{~cm}^{-1}\left(\omega_{\gamma, \delta} \mathrm{C}-\mathrm{H}\right.$ of aromatic compounds). In addition, the $\mathrm{Si}-\mathrm{O}-\mathrm{Si}$ peaks of the hybrid silica are clearly visible in the agglomerates, which confirms the inclusion of the microplastic in a hybrid silica gel during the fixation process.

\subsubsection{TGA}

For the TGA measurements, the removal experiments were additionally conducted with mixtures of different polymer types. The data (Figure 9 and Figures S8-S10) show that 
the agglomerates include the different polymers and the organosilane based hybrid silica formed during the fixation process. Thus, the fixation process is also suitable to remove mixtures of different polymers. The peak at $414{ }^{\circ} \mathrm{C}$ can be assigned to PES, the peak at $475^{\circ} \mathrm{C}$ results from the overlapping PE, PP and PA peaks and the first peak of the hybrid silica at $515{ }^{\circ} \mathrm{C}$. The peak at $610^{\circ} \mathrm{C}$ and the continuing weight loss after $505{ }^{\circ} \mathrm{C}$, where the polymers show no weight loss anymore, confirm the presence of the hybrid silica in the agglomerate. Due to the overlapping of the TGA peaks, a quantitative analysis of the composition of the agglomerate was not possible.

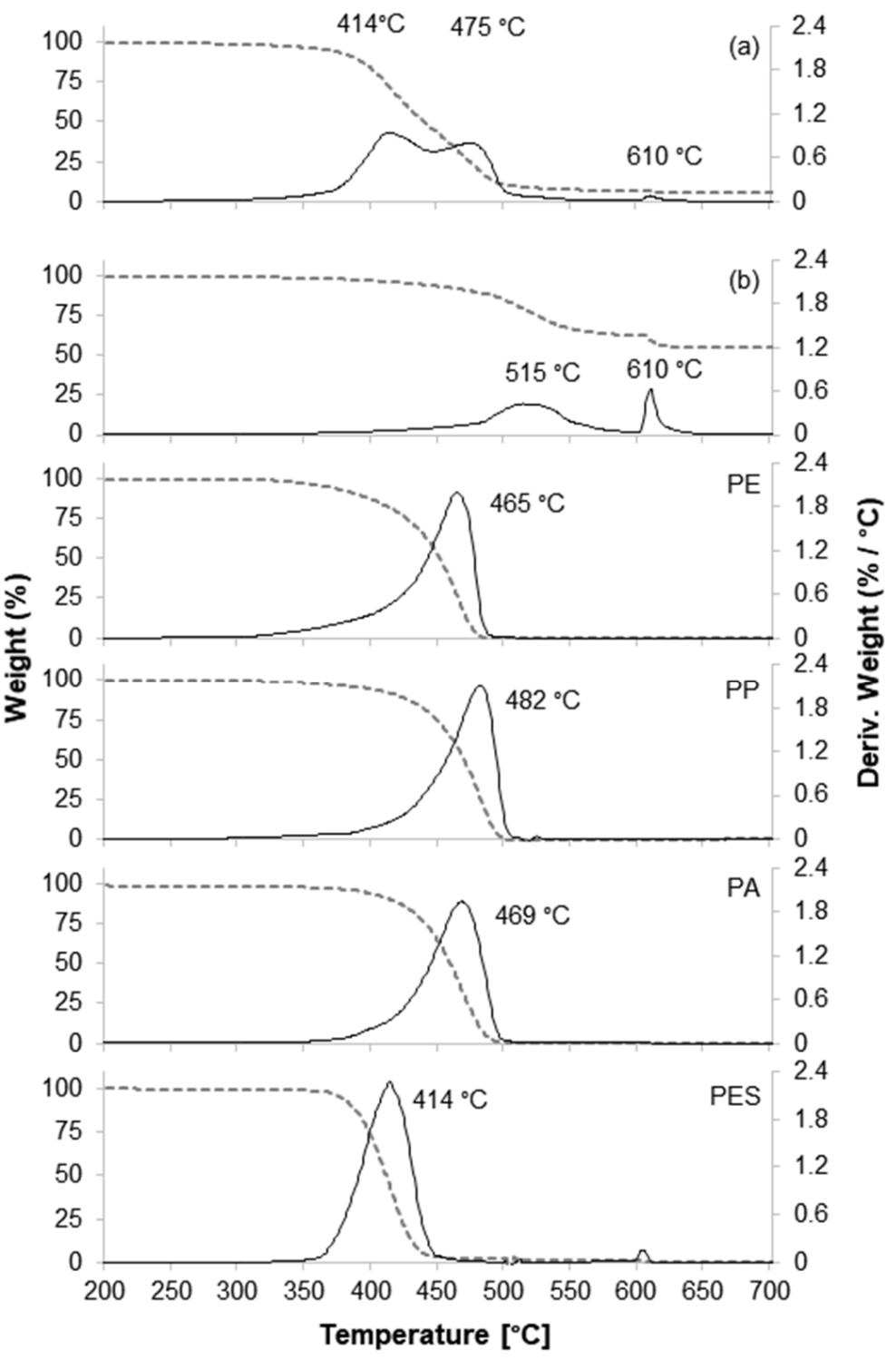

Figure 9. TGA curves of (a) agglomerate formed in removal process $100 \mathrm{mg}$ of PE/PP/PA/PES (1:1:1:1) from $1 \mathrm{~L}$ demineralized water using $100 \mu \mathrm{L}$ n-Butyltrichlorosilane; (b) hybrid silica formed by adding $100 \mu \mathrm{L}$ n-Butyltrichlorosilane in $1 \mathrm{~L}$ demineralized water and different polymer types used in experiments. Grey dashed line $=$ weight in $\%$; black line $=$ derived weight in $\% /{ }^{\circ} \mathrm{C}$.

\section{Conclusions}

In summary, this study showed that the novel method of microplastic removal using organosilanes has a huge potential to be applied for microplastic removal on technical scale. Temperature and water type, here salt water and biologically treated municipal wastewater, show no negative effect on microplastic removal with organosilanes, which shows the robustness of the method and should make it easily transferable to processes as advanced 
wastewater treatment or sea water using processes. As wastewater composition can vary strongly depending on the catchment area, weather and climatic conditions, further investigations are needed to ensure the applicability in different wastewaters. Also, application in highly saline lakes could pose a challenge to the process.

It was also shown that the chemical composition and surface chemistry of microplastics have a strong influence on the removal process and physical interaction with the organosilanes. The removal efficiency of microplastics based on different polymer types decreases with the increasing polarity of the polymer. Highly polar polymers can be removed more efficiently by increasing the polarity of the organic group. However, this leads to a reduced effectiveness towards non-polar polymers. These results show that the organosilanes can be adapted specifically to improve the removal of certain polymer types by adjusting the organic group to the surface chemistry of the polymer. The high variability and modifiability of organosilanes makes them a very promising substance class for this challenge. Another alternative to increase the efficiency is using higher concentrations of organosilanes. Further studies should focus on the combination of different organosilanes for an effective removal of mixtures of polar and non-polar polymers, as they occur in the environment. Also, the effect of biofilm coverage, weathering and natural organic matter adsorption can be taken into consideration.

The analysis of the size composition of the microplastics and agglomerates shows a strong increase in size during the agglomeration process for all polymer types. However, the limit of $1 \mathrm{~mm}$ for the agglomerates for efficient removal on pilot plant scale is often not achieved. An improved removal process for the agglomerates with a lower size limit is therefore expected to lead to strongly improved microplastic removal on technical scale.

From the tested organosilanes n-butyltrichlorosilane and isooctyltrichlorosilane both show high quantities of residues dissolved in water after the removal process, ranging from 76.4 to $46.3 \%$. PE-X shows no dissolved residues and therefore is perfectly suited for the application on technical scale without posing any risk of the introduction of organosilanes into the environment or technical processes, which is a big advantage of this specific organosilane. The tested water compositions show no significant differences on the amount of residues. To control dissolved organosilanes residues, ICP-OES showed more precise and reliable results than DOC measurements. But as a cheaper and faster method, DOC is still suitable for an efficient process control in possible technical applications.

Microscope images, IR-spectra and TGA curves confirm the inclusion of the microplastics in a hybrid silica formed by a water induced sol-gel process during the fixation process The TGA curves can additionally show that it is possible to fix mixtures of different polymers simultaneously in the agglomerates. Therefore, these methods are well suited to investigate the composition of agglomerates and later on to control the process during continuous application.

Due to the limitations of the laboratory scale test setup, $100 \mathrm{mg} / \mathrm{L}$ could be selected here as the smallest concentration of microplastics. However, environmental concentrations are usually far below that concentration. Therefore, further pilot-plant studies will focus on a reduction of the microplastics concentrations as well as the function in real applications without microplastic spiking. Also, a broader variety of water compositions is going to be tested. Due to the adaptability of this process to different polymer types and the low technical effort for the application on technical scale, we see a high potential for this process to be a cost-effective and easily applicable alternative for standard flocculants.

Supplementary Materials: The following are available online at https:/ / www.mdpi.com/2073-4 441/13/5/675/s1, Figure S1: Stereomicroscope images of raw microplastics used for the fixation experiments. Table S1: Water parameters of a $24 \mathrm{~h}$ composite sample taken on 2nd March 2020 at the effluent of the sewage treatment plant Landau i. d. Pfalz, Germany. Figure S2: FTIR-Spectra of the microplastics used in the fixation experiments. Figure S3: FTIR-Spectra of the hybrid silica formed by adding the respective organosilane to water and stirring for $20 \mathrm{~min}$. Figure S4: FTIR-Spectra of the agglomerates formed during the fixation process using PE-X and different polymers. Figure S5: FTIR-Spectra of the agglomerates formed during the fixation process using $n$-butyltrichlorosilane and 
different polymers. Figure S6: FTIR-Spectra of the agglomerates formed during the fixation process using isooctyltrichlorosilane and different polymers. Figure S7: FTIR-Spectra of the agglomerates formed during the fixation process using (3-chloropropyl)trichlorosilane and different polymers. Note: Using (3-chloropropyl)trichlorosilane and PE/PP, no agglomerates were formed during the fixation experiments. Figure S8: TGA curves of (a) agglomerate formed in removal process $100 \mathrm{mg}$ of PVC from $1 \mathrm{~L}$ demin. water using $100 \mu \mathrm{L}$ PE-X; (b) hybrid silica formed by adding $100 \mu \mathrm{L}$ PE-X in $1 \mathrm{~L}$ demin. water and of the different polymer types used in experiments. Figure S9: TGA curves of (a) agglomerate formed in removal process $100 \mathrm{mg}$ of PES from $1 \mathrm{~L}$ demin. water using $100 \mu \mathrm{L}$ Isooctyltrichlorosilane; (b) hybrid silica formed by adding $100 \mu \mathrm{L}$ Isooctyltrichlorosilane in $1 \mathrm{~L}$ demin. water and of PES. Figure S10: TGA curves of (a) agglomerate formed in removal process $100 \mathrm{mg}$ of PE/PA (1:1) from $1 \mathrm{~L}$ demin. water using $100 \mu \mathrm{L}$ PE-X; (b) hybrid silica formed by adding $100 \mu \mathrm{L}$ $\mathrm{PE}-\mathrm{X}$ in $1 \mathrm{~L}$ demin. water and of the polymer types used in experiments.

Author Contributions: Conceptualization, M.T.S. and K.S.; methodology, M.T.S., K.S. and H.H.; formal analysis, M.T.S.; investigation, M.T.S.; resources, H.H. and K.S.; data curation, M.T.S.; writingoriginal draft preparation, M.T.S. and K.S.; writing—review and editing, M.T.S.; visualization, M.T.S.; supervision, K.S. and H.H.; project administration, K.S. and H.H.; funding acquisition, K.S. and H.H. All authors have read and agreed to the published version of the manuscript.

Funding: This study was not part of a special funded project.

Institutional Review Board Statement: Not applicable.

Informed Consent Statement: Not applicable.

Data Availability Statement: The data presented in this study is available in the current manuscript, raw data is available on request from the corresponding author.

Acknowledgments: The research projects of Wasser 3.0 (www.wasserdreinull.de, accessed on 2 March 2020) are conducted by sponsors and donors. Wasser $3.0 \mathrm{gGmbH}$ is a non-profit company with strong focus on responsible research, education, and communication. The enterprise abcr $\mathrm{GmbH}$ (www.abcr.de, accessed on 2 March 2020) from Karlsruhe (GERMANY) is directly involved in the project as an industrial partner. The authors acknowledge special support from abcr service lab and Dennis Schober from EW Landau for the fruitful discussion about the microplastic removal. Michael Sturm additionally thanks the 'Deutsche Bundesstiftung Umwelt' (DBU) for the grant of a PhD scholarship (Az. 20018/549).

Conflicts of Interest: The authors declare no conflict of interest.

\section{References}

1. Barnes, D.K.A.; Galgani, F.; Thompson, R.C.; Barlaz, M. Accumulation and fragmentation of plastic debris in global environments. Philos. Trans. R. Soc. B Biol. Sci. 2009, 364, 1985-1998. [CrossRef]

2. Law, K.L.; Thompson, R.C. Microplastics in the seas. Science 2014, 345, 144-145. [CrossRef]

3. Siegfried, M.; Koelmans, A.A.; Besseling, E.; Kroeze, C. Export of microplastics from land to sea. A modelling approach. Water Res. 2017, 127, 249-257. [CrossRef] [PubMed]

4. Da Costa, J.P.; Santos, P.S.M.; Duarte, A.C.; Rocha-Santos, T. (Nano)plastics in the environment-Sources, fates and effects. Sci. Total Environ. 2016, 566-567, 15-26. [CrossRef] [PubMed]

5. Horton, A.A.; Walton, A.; Spurgeon, D.J.; Lahive, E.; Svendsen, C. Microplastics in freshwater and terrestrial environments: Evaluating the current understanding to identify the knowledge gaps and future research priorities. Sci. Total Environ. 2017, 586, 127-141. [CrossRef]

6. Gasperi, J.; Wright, S.L.; Dris, R.; Collard, F.; Mandin, C.; Guerrouache, M.; Langlois, V.; Kelly, F.J.; Tassin, B. Microplastics in air: Are we breathing it in? Curr. Opin. Environ. Sci. Health 2018, 1, 1-5. [CrossRef]

7. Borrelle, S.B.; Ringma, J.; Law, K.L.; Monnahan, C.C.; Lebreton, L.; McGivern, A.; Murphy, E.; Jambeck, J.; Leonard, G.H.; Hilleary, M.A.; et al. Predicted growth in plastic waste exceeds efforts to mitigate plastic pollution. Science 2020, 369, 1515-1518. [CrossRef] [PubMed]

8. Jambeck, J.R.; Geyer, R.; Wilcox, C.; Siegler, T.R.; Perryman, M.; Andrady, A.; Narayan, R.; Law, K.L. Plastic waste inputs from land into the ocean. Science 2015, 347, 768-771. [CrossRef]

9. Wright, S.L.; Kelly, F.J. Plastic and Human Health: A Micro Issue? Environ. Sci. Technol. 2017, 51, 6634-6647. [CrossRef]

10. Galloway, T.S.; Cole, M.; Lewis, C. Interactions of microplastic debris throughout the marine ecosystem. Nat. Ecol. Evol. 2017, 1, 116. [CrossRef] 
11. Schuhen, K.; Sturm, M.T. Microplastic Pollution and Reduction Strategies. In Handbook of Microplastics in the Environment; Rocha-Santos, T., Costa, M., Mouneyrac, C., Eds.; Springer International Publishing: Cham, Switzerland, 2020; pp. 1-33. ISBN 978-3-030-10618-8.

12. Sun, J.; Dai, X.; Wang, Q.; van Loosdrecht, M.C.M.; Ni, B.-J. Microplastics in wastewater treatment plants: Detection, occurrence and removal. Water Res. 2019, 152, 21-37. [CrossRef] [PubMed]

13. Ma, B.; Xue, W.; Hu, C.; Liu, H.; Qu, J.; Li, L. Characteristics of microplastic removal via coagulation and ultrafiltration during drinking water treatment. Chem. Eng. J. 2019, 359, 159-167. [CrossRef]

14. Peixoto, D.; Pinheiro, C.; Amorim, J.; Oliva-Teles, L.; Guilhermino, L.; Vieira, M.N. Microplastic pollution in commercial salt for human consumption: A review. Estuar. Coast. Shelf Sci. 2019, 219, 161-168. [CrossRef]

15. EFSA CONTAM Panel. Presence of microplastics and nanoplastics in food, with particular focus on seafood. Efsa J. 2016, 14, e04501. [CrossRef]

16. Bui, X.-T.; Vo, T.-D.-H.; Nguyen, P.-T.; Nguyen, V.-T.; Dao, T.-S.; Nguyen, P.-D. Microplastics pollution in wastewater: Characteristics, occurrence and removal technologies. Environ. Technol. Innov. 2020, 19, 101013. [CrossRef]

17. Pico, Y.; Alfarhan, A.; Barcelo, D. Nano- and microplastic analysis: Focus on their occurrence in freshwater ecosystems and remediation technologies. Trac. Trends Anal. Chem. 2019, 113, 409-425. [CrossRef]

18. Poerio, T.; Piacentini, E.; Mazzei, R. Membrane Processes for Microplastic Removal. Molecules 2019, 24, 4148. [CrossRef]

19. Talvitie, J.; Mikola, A.; Koistinen, A.; Setälä, O. Solutions to microplastic pollution-Removal of microplastics from wastewater effluent with advanced wastewater treatment technologies. Water Res. 2017, 123, 401-407. [CrossRef]

20. Wang, Y.; Li, Y.N.; Tian, L.; Ju, L.; Liu, Y. The removal efficiency and mechanism of microplastic enhancement by positive modification dissolved air flotation. Water Environ. Res. 2020. [CrossRef]

21. Lapointe, M.; Farner, J.M.; Hernandez, L.M.; Tufenkji, N. Understanding and Improving Microplastic Removal during Water Treatment: Impact of Coagulation and Flocculation. Environ. Sci. Technol. 2020, 54, 8719-8727. [CrossRef]

22. Harford, A.J.; Hogan, A.C.; Jones, D.R.; van Dam, R.A. Ecotoxicological assessment of a polyelectrolyte flocculant. Water Res. 2011, 45, 6393-6402. [CrossRef] [PubMed]

23. Pereira, J.L.; Vidal, T.; Gonçalves, F.J.M.; Gabriel, R.G.; Costa, R.; Rasteiro, M.G. Is the aquatic toxicity of cationic polyelectrolytes predictable from selected physical properties? Chemosphere 2018, 202, 145-153. [CrossRef] [PubMed]

24. Herbort, A.F.; Schuhen, K. A concept for the removal of microplastics from the marine environment with innovative host-guest relationships. Environ. Sci. Pollut. Res. 2016, 11061-11065. [CrossRef] [PubMed]

25. Herbort, A.F.; Sturm, M.T.; Schuhen, K. A new approach for the agglomeration and subsequent removal of polyethylene, polypropylene, and mixtures of both from freshwater systems-A case study. Environ. Sci. Pollut. Res. Int. 2018, 15226-15234. [CrossRef] [PubMed]

26. Herbort, A.F.; Sturm, M.T.; Fiedler, S.; Abkai, G.; Schuhen, K. Alkoxy-silyl Induced Agglomeration: A New Approach for the Sustainable Removal of Microplastic from Aquatic Systems. J. Polym. Environ. 2018, 62, 4258-4270. [CrossRef]

27. Sturm, M.T.; Herbort, A.F.; Horn, H.; Schuhen, K. Comparative study of the influence of linear and branched alkyltrichlorosilanes on the removal efficiency of polyethylene and polypropylene-based microplastic particles from water. Environ. Sci. Pollut. Res. 2020, 27, 10888-10898. [CrossRef]

28. Schuhen, K.; Sturm, M.T.; Herbort, A.F. Technological Approaches for the Reduction of Microplastic Pollution in Seawater Desalination Plants and for Sea Salt Extraction. In Plastics in the Environment; Gomiero, A., Ed.; IntechOpen: London, UK, 2019; ISBN 978-1-83880-492-3.

29. Brinker, C.J.; Scherer, G.W. Sol-gel Science: The physics and Chemistry of sol-gel Processing; Academic Press: Boston, MA, USA, 1990; ISBN 978-0-12-134970-7.

30. Gurung, K.; Ncibi, M.C.; Sillanpää, M. Assessing membrane fouling and the performance of pilot-scale membrane bioreactor (MBR) to treat real municipal wastewater during winter season in Nordic regions. Sci. Total Environ. 2017, 579, 1289-1297. [CrossRef]

31. Shore, J.L.; M'Coy, W.S.; Gunsch, C.K.; Deshusses, M.A. Application of a moving bed biofilm reactor for tertiary ammonia treatment in high temperature industrial wastewater. Bioresour. Technol. 2012, 112, 51-60. [CrossRef]

32. Henze, M. Wastewater Treatment: Biological and Chemical Processes, 3rd ed.; Springer: New Delhi, India, 2010; ISBN 9783540422280.

33. Akarsu, C.; Kumbur, H.; Gökdağ, K.; Kıdeyş, A.E.; Sanchez-Vidal, A. Microplastics composition and load from three wastewater treatment plants discharging into Mersin Bay, north eastern Mediterranean Sea. Mar. Pollut. Bull. 2020, 150, 110776. [CrossRef]

34. Ben-David, E.A.; Habibi, M.; Haddad, E.; Hasanin, M.; Angel, D.L.; Booth, A.M.; Sabbah, I. Microplastic distributions in a domestic wastewater treatment plant: Removal efficiency, seasonal variation and influence of sampling technique. Sci. Total Environ. 2021, 752, 141880. [CrossRef]

35. Ranade, V.V.; Bhandari, V.M.; Ahirrao, S. Industrial Wastewater Treatment, Recycling, and Reuse; Butterworth-Heinemann: Kidlington, Oxford, UK; Waltham, MA, USA, 2014; ISBN 9780444634030.

36. Elderfield, H.; Holland, H.D. (Eds.) The Oceans and Marine Geochemistry, 1st ed.; Elsevier: Amsterdam, The Netherlands, 2006; ISBN 9780080451015.

37. Hammer, U.T. Saline Lake Ecosystems of the World; Junk: Dordrecht, The Netherlands, 1986; ISBN 9061935350.

38. Rosner, D.; Markowitz, G. Persistent pollutants: A brief history of the discovery of the widespread toxicity of chlorinated hydrocarbons. Environ. Res. 2013, 120, 126-133. [CrossRef] [PubMed] 
39. Hurkes, N.; Ehmann, H.M.A.; List, M.; Spirk, S.; Bussiek, M.; Belaj, F.; Pietschnig, R. Silanol-based surfactants: Synthetic access and properties of an innovative class of environmentally benign detergents. Chemistry 2014, 20, 9330-9335. [CrossRef] [PubMed]

40. Baby, D.K. Rheology of hydrogels. In Rheology of Polymer Blends and Nanocomposites; Elsevier: Amsterdam, The Netherlands, 2020; pp. 193-204. ISBN 9780128169575.

41. Al-Oweini, R.; El-Rassy, H. Synthesis and characterization by FTIR spectroscopy of silica aerogels prepared using several Si(OR)4 and $\mathrm{R}^{\prime \prime} \mathrm{Si}\left(\mathrm{OR}^{\prime}\right) 3$ precursors. J. Mol. Struct. 2009, 919, 140-145. [CrossRef]

42. Noda, I.; Dowrey, A.E.; Haynes, J.L.; Marcott, C. Group Frequency Assignments for Major Infrared Bands Observed in Common Synthetic Polymers. In Physical Properties of Polymers Handbook; Mark, J.E., Ed.; Springer: New York, NY, USA, 2007 ; pp. 395-406. ISBN 978-0-387-31235-4.

43. Jung, M.R.; Horgen, F.D.; Orski, S.V.; Rodriguez, C.V.; Beers, K.L.; Balazs, G.H.; Jones, T.T.; Work, T.M.; Brignac, K.C.; Royer, S.-J.; et al. Validation of ATR FT-IR to identify polymers of plastic marine debris, including those ingested by marine organisms. Mar. Pollut. Bull. 2018, 127, 704-716. [CrossRef] [PubMed] 